\title{
Platform Patterns_-Using Proven Principles to Develop Digital Platforms
}

\author{
Marvin Drewel $^{1} \mathbb{D} \cdot$ Leon Özcan $^{1} \cdot$ Jürgen Gausemeier $^{1} \cdot$ Roman Dumitrescu $^{1}$
}

Received: 27 February 2020 / Accepted: 14 February 2021 / Published online: 10 March 2021

(c) The Author(s) 2021

\begin{abstract}
Hardly any other area has as much disruptive potential as digital platforms in the course of digitalization. After serious changes have already taken place in the B2C sector with platforms such as Amazon and Airbnb, the B2B sector is on the threshold to the so-called platform economy. In mechanical engineering, pioneers like GE (PREDIX) and Claas (365FarmNet) are trying to get their hands on the act. This is hardly a promising option for small and medium-sized companies, as only a few large companies will survive. Small and medium-sized enterprises (SMEs) are already facing the threat of losing direct consumer contact and becoming exchangeable executers. In order to prevent this, it is important to anticipate at an early stage which strategic options exist for the future platform economy and which adjustments to the product program should already be initiated today. Basically, medium-sized companies in particular lack a strategy for an advantageous entry into the future platform economy.

The paper presents different approaches to master the challenges of participating in the platform economy by using platform patterns. Platform patterns represent proven principles of already existing platforms. We show how we derived a catalogue with 37 identified platform patterns. The catalogue has a generic design and can be customized for a specific use case. The versatility of the catalogue is underlined by three possible applications: (1) platform ideation, (2) platform development, and (3) platform characterization.
\end{abstract}

Keywords Digitalization · Digital platforms · Platform economy · Foresight · Strategic product planning $\cdot$ Multisided markets $\cdot$ B2B-platforms $\cdot$ Platform markets

Marvin Drewel

marvin.drewel@hni.uni-paderborn.de

Extended author information available on the last page of the article 


\section{The Disruptive Potential of Digital Platforms}

In the course of digitization, the concept of digital platforms or IT platforms has been the subject of a veritable hype in recent years (Engels et al.,, 2017) and is experiencing an impressive renaissance (Linz et al., 2017). Digital platforms are putting established companies across industries under pressure. Former wellestablished enterprises like Nokia or Blackberry are now dominated by platform enterprises like Apple. Based on these changes, van Alstyne et al. have formulated the somewhat bold thesis that "only those who understand the principle and transform their business model will survive" (Alstyne et al., 2016). Up to now, this thesis has been mainly applied to the business-to-consumer (B2C) sector. There, digital platforms such as Uber, Airbnb, or Amazon have radically changed their industries and displaced formerly established companies (Libert et al., 2016). At present, such a development is also apparent in the B2B sector and here in particular in mechanical engineering and related sectors such as the electronics industry, automotive industry, or medical technology (Lerch et al., 2019). Leading companies are stepping out of their core business and develop own platforms. Additionally, agile start-ups begin to build platform solutions and services for digital platforms (Koldewey et al., 2019). Driven by digitization, such platforms can link actors who have never been in contact with each other (Altman et al., 2013).

Following Parker et al., the disruptive potential of digital platforms is based on two major economic advantages: (1) marginal costs and (2) network effects. These advantages enable companies to expand their platform businesses with relatively low investments compared with traditional businesses (Cusumano et al., 2019; Parker et al., 2017). Marginal costs describe the additional costs that occur if an additional unit of a certain product or service is being produced (O'Sullivan \& Sheffrin, 2003). For instance, if the Hilton Worldwide Holdings Inc. decides to expand to a new market, they need to invest in new buildings and new personal staff. Contrary to this, if Airbnb decides to expand to a new market, they do not need such investments. The new accommodations are provided by private home owners who also act as staff for the consumers of Airbnb. The additional costs for these new accommodations are almost not existing which allows platforms to expand their business with minimal costs, once their platforms are established and running (Alstyne et al., 2016).

The network effect describes how the consumer value of a product changes when the number of consumers of the same product or complementary products changes. A distinction is made between the direct and indirect network effect. The direct network effect was described in 1986 by Katz and Shapiro and states that a product's value changes with the total number of consumers of that product (Farrell \& Saloner, 1992; Funk, 2009; Katz \& Shapiro, 1986). Often referred examples for this effect are telephones and fax machines. Within the context of digital platforms, the direct network effect occurs, e.g., on social media platforms such as Facebook. The indirect network effect occurs when the value of a product changes as soon as the number of consumers of another product changes without 


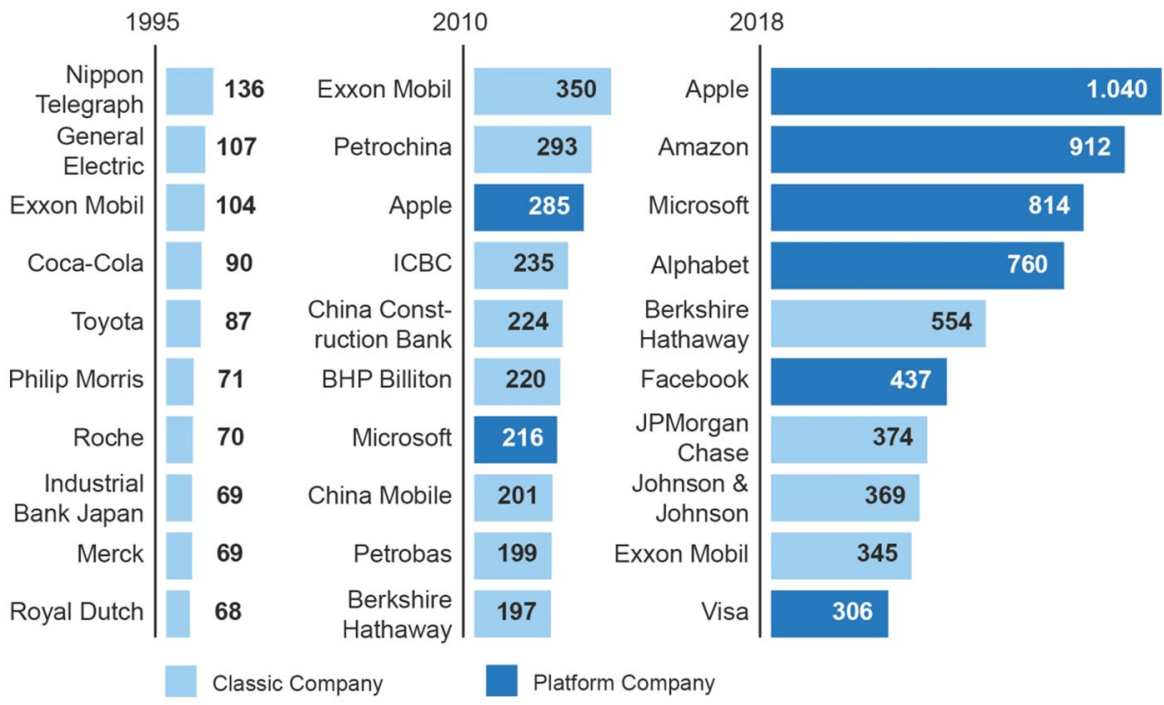

Fig. 1 The ten most valuable companies from 1995 to 2018 by market capitalization in billion US dollars (fortiss Gmbh, 2016; Kempe, 2011; Payment \& Banking, 2019)

a direct relationship between these products (Shapiro \& Varian, 1998). The indirect network effect is characteristic for two- or multisided markets. Thereby, an increased number of participants on the one side of the market tends to increase the number of participants on the other side of the market. This effect is the driving force behind digital platforms like Airbnb or Uber. Positive network effects are the foundation for digital platforms. Thus, the more participants a platform has, the more attractive it becomes for other participants. This is referred to as self-reinforcing "chain reactions" which—once initiated-lead to the rapid growth of digital platforms. This is the reason why for each market only a very limited number of platforms can economically exist (Eisenmann et al., 2006). An analysis of the historical development of the most valuable companies worldwide impressively visualizes the disruptive potential of digital platforms (Fig. 1). While classic companies dominated the ranking in 1995, six of the ten most valuable companies were platform companies in $2018 .{ }^{1}$ It is striking that the number of valuable platform companies has increased rapidly in recent times.

Companies can conduct classic activities along an input/output process and create a platform ecosystem while doing so. For example, the development, production, and distribution of Apple's iPhone follow a classic value chain. At the same

\footnotetext{
${ }^{1}$ In order to distinguish classic companies from platform companies, the term pipeline company has established itself in the scientific literature. Classic companies operate according to the value chain described by Porter in 1985. The dominant activities of these companies take place in a classical input/ output process (Porter, 1985). Platform companies on the other hand place the operation of a digital platform at the center of their business activities and pursue the goal of maximum ecosystem value (Parker et al., 2017).
} 
time, Apple has created a platform ecosystem around its iOS operating system in which the iPhone is embedded. With the introduction of the iOS platform in 2007, Apple was able to capture a significant share of the global smartphone market within just a few years. Apple's core business is the sale of hardware components, which accounts for $80 \%$ of its revenues. However, the success of the company and thus also the sale of the hardware is significantly influenced by the platform character of the company (Reillier \& Reillier, 2017). In the following section, we will discuss the way digital platforms work in order to understand the reasons for the success of digital platforms.

\section{The Way Digital Platforms Work and Why Established Enterprises Struggle with It}

The success of a digital platform is not based on internal resources, but on the ecosystem in which the platform is embedded. The acatech-National Academy of Science and Engineering takes up the concept of the platform ecosystem and states that a platform ecosystem describes the economic mechanisms behind digital platforms as well as the stakeholders involved and their relationships (Engels et al., 2017). According to Evans and Schmalensee, these stakeholders include all persons, companies, institutions, and other environmental factors that influence the value created by a platform (Evans \& Schmalensee, 2016). This value is created by platforms using stakeholder data to orchestrate physical and digital resources across the ecosystem (Choudary, 2015). We therefore understand a digital platform as a two or multisided market in which the different actors are brought together by an intermediary and propose an arrangement of roles within a digital platform as shown in Fig. 2. The different actors are assigned to the category platform core, platform participants, and platform environment (Drewel et al., 2018). If, for example, the number of producers increases, the platform becomes more attractive for consumers and vice versa (Eisenmann et al., 2006).

The core value of a platform company is not a classic physical value unit, but an infrastructure that enables interactions between producers and consumers. The design of the key interaction is therefore the core of each digital platform. The key interaction is the reason why participants use digital platforms (Jaekel, 2017; Parker et al., 2017). The anatomy of a key interaction consists of four characteristics (Choudary, 2015), (Moazed \& Johnson, 2016):

(1) Value creation: Each key interaction involves at least one producer who creates the value unit. The production of value units by the producer marks the starting point of a platform interaction (Parker et al., 2017), (Jaekel, 2017), (Moazed \& Johnson, 2016).

(2) Connection: The connection of producers and consumers is enabled through filtering and individualization of the platform content. Filtering ensures that only high-quality value units are offered. Filter mechanisms support desirable and punish undesirable behavior (Choudary, 2015; Jaekel, 2017). With the help of filters, a specific consumer gains access to the content relevant to him. Digital 


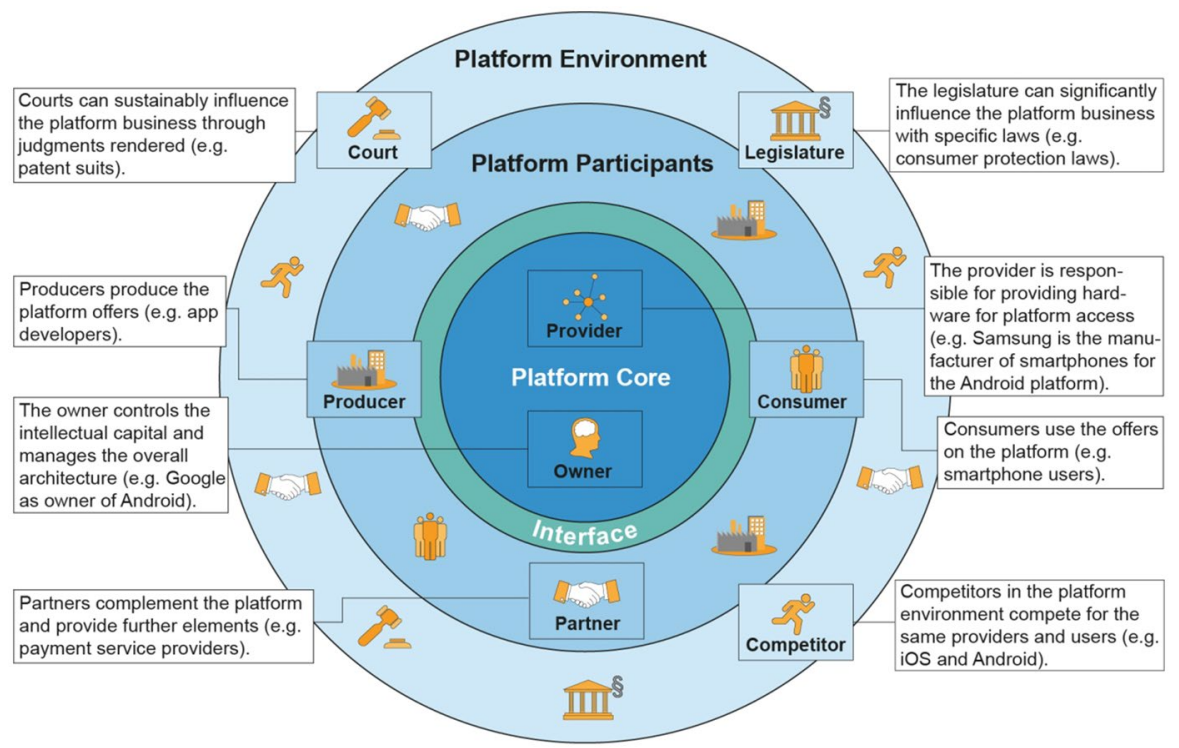

\begin{tabular}{|c|c|c|c|}
\hline Platform Core & Interface & Platform Participants & Platform Environment \\
\hline $\begin{array}{l}\text { Contains the infrastructure provided } \\
\text { by a platform and the companies } \\
\text { involved. }\end{array}$ & $\begin{array}{l}\text { The actors involved in an interaction } \\
\text { access the platform infrastructure } \\
\text { via an interface. }\end{array}$ & $\begin{array}{l}\text { Includes all actors directly involved } \\
\text { in an interaction. }\end{array}$ & $\begin{array}{l}\text { Players who are not directly involved } \\
\text { but who nevertheless influence the } \\
\text { platform business. }\end{array}$ \\
\hline
\end{tabular}

Fig. 2 Roles in a digital platform (Baums, 2015; Drewel et al., 2018; Tiwana, 2014)

platforms that are able to provide their consumers with individualized content encourage them to continue participating (Parker et al., 2017).

(3) Consumption: Each key interaction involves at least one platform participant who consumes the value unit that is relevant for him or her. Consumption can take different forms depending on the value unit. For example, the consumption of digital value units often takes place directly via the platform (Choudary, 2015; Jaekel, 2017; Moazed \& Johnson, 2016).

(4) Compensation: The key interaction is completed with compensation. It is characteristic that the consumer transmits a return service to the producer for the value unit received (Moazed \& Johnson, 2016).

In a key interaction, information, value units, and payments are exchanged between the platform participants. A producer and a consumer first exchange information. Then, the producer transmits a value unit to the consumer and receives a payment in return. The payment does not always have to be monetary, but can also take the form of data, evaluations, etc. The payment can also be made in form of a payment slip. The number of key interactions increases with the scope of services/products offered and the number of participants in the platform ecosystem. The constantly repeating key interactions are made possible by three basic functions of a platform (Choudary, 2015; Cusumano et al., 2019; Moazed \& Johnson, 2016; Parker et al., 2017): 


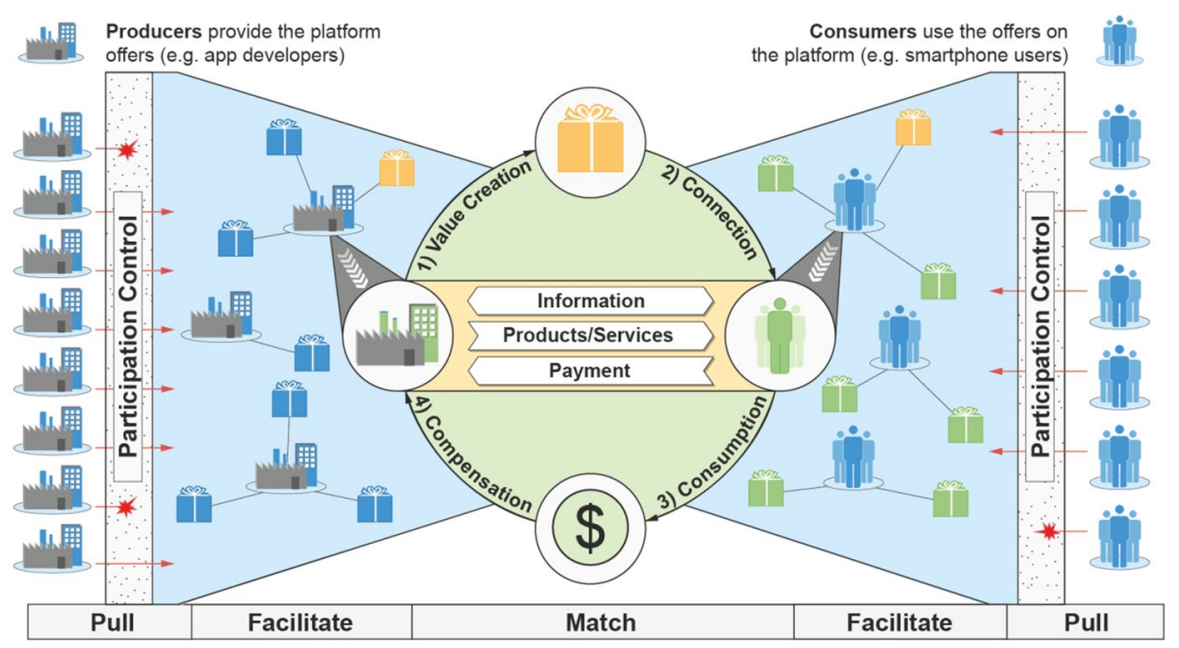

Fig. 3 Aggregated representation of the functionality of a digital platform

- Match: The most relevant value units must always be provided for the consumers. With an increasing number of producers, the scope of the platform offerings increases, making it more difficult for consumers to identify the desired offer. Filters are suitable for merging the value unit provided by the producer with the corresponding consumer.

- Facilitate: Platform companies do not control value creation, but provide an infrastructure that enables value creation. Programs are introduced and policies established that regulate interactions and promote desired behavior. Filter mechanisms ensure that high-quality content is provided on the platform and that desirable interactions are enabled.

- Pull: Key interactions are made possible by luring participants to the platform and keeping them there. Platforms have to overcome the chicken and egg problem (Who joins the platform first? Producer or consumer?). The aim is to make participation on the platform as easy as possible for potential participants. Since the focus of business activities is on repetitive interactions, it must be ensured that the participants are regularly active. In order to prevent unwanted behavior of the platform participants, membership checks can be useful.

In summary, the pull effect enables the quantitative scaling of a platform by promoting production and consumption. Filter mechanisms ensure that the quality of the consumer experience is guaranteed as the platform grows (Jaekel, 2017). On the basis of the filtered and individualized content, suitable producers and consumers can interact in key interactions and initiate the exchange. Figure 3 shows an aggregated representation of the functionality of a digital platform.

While the awareness of the economic potential of the platform model is growing (Evans \& Gawer, 2016), many established companies have considerable difficulties mastering the challenges of developing own platforms and initiating the 
powerful chain reactions based on network effects (Parker et al., 2017). Two reasons for this are the lack of knowledge concerning the development of digital platforms and new ways to monetarize the platform business (Engels et al., 2017). Evans and Schmalensee underline the lack of knowledge concerning multisided markets and the connected difficulties in understanding how digital platforms work as a central challenge (Evans \& Schmalensee, 2016). Choudary describes three primary shifts in the way towards multisided markets (Choudary, 2015):

(1) Shift in markets: Traditionally, the consumer was at the end of a pipeline where producers produced the good for the consumer. Digital platforms do not create the end value but enable value creation between various producers and consumers. As a result, participants on digital platforms can take on production as well as consumption.

(2) Shift in competitive advantage: Pipeline enterprises compete through managing resources and intellectual property. This does not apply to digital platforms. Platform enterprises focus on orchestrating and enabling value-exchanging interactions and using data about the various participants within the ecosystem. The management of ecosystems is therefore the key competitive advantage in platform economies.

(3) Shift in value creation: The value in pipeline markets is created through processes that organize a company's labor and resources. Such markets focus on the efficiency of business processes. The value creation in platform markets, however, is focused on the number and quality of interactions. It is based on orchestrating these interactions between consumers and producers.

The three described shifts show that the rules in platform markets are completely different from pipeline markets. The way companies interact with markets, build competitive advantage, and create value is new for the majority of traditional companies. The disruptive potential of digital platforms is promising for those companies that are able to establish a digital platform, but involves some risks that are connected to the development of a platform:

- Reaching critical mass is a prerequisite for entering the lucrative growth phase of a digital platform. To achieve this, platform owners must overcome the chicken-and-egg problem, which has already caused many platforms to fail (Caillaud \& Jullien, 2003).

- Digital platforms require high investments in the underlying IT infrastructure. Furthermore, in the first phases of a platform's life, a considerable marketing effort is necessary to attract sufficient participants. Platform operators need a high amount of money to bridge the initial costs (Libert et al., 2016).

- The platform owner must be aware of the risk of liability issues. The unclear legal situation currently leads to an increased liability of platform operators (Härting, 2015).

- Digital platforms are changing the way companies create value. For traditional pipeline activities, the focus is on maximizing consumer value; for platform 
activities, the focus is on maximizing ecosystem value. This may require subsidizing certain consumer groups to attract others. These changes are often confronted with opponents within your own company (Parker et al., 2017).

- Building a digital platform requires new skills (e.g., developing platform business models) and resources (new IT systems), which are often not available in established companies. Especially for small- and medium-sized enterprises, the development of the necessary skills represents a risk when entering the platform economy (Engels et al., 2017).

The development of a platform is associated with significant opportunities such as increased sales and consumer loyalty. However, companies must also be aware of the risks. Many platforms fail to achieve critical mass and the high initial costs of successful platform operation. Small- and medium-sized companies in particular lack opportunities to enter the platform economy. These companies need knowledge of existing platforms and best practices to master the leap into the platform economy. These knowledge deficits of companies can be eliminated by using patterns. Platform patterns represent proven principles of already existing platforms. Therefore, they are considered in the following analysis of approaches to develop digital platforms.

\section{Approaches to Develop Digital Platforms}

There are several approaches in the scientific literature that are dedicated to the entry into the platform economy. These can be roughly divided into three categories: (1) canvas-based approaches to design a platform business, (2) specific approaches to develop digital platforms, and (3) pattern-based approaches to develop digital platforms.

(1) Canvas-based approaches: In holistic framework models, several relevant elements of digital platforms are considered in aggregated form. The aim of these framework models is to support companies in planning and building their own digital platforms. An example is provided by Choudary, who describes a four-stage process for building a digital platform based on key interaction. This construction process is tangled by a platform canvas, which shows all elements relevant for the platform construction (Choudary, 2015). Similar canvas-based approaches for platform construction are provided by Walter and Lohse as well as Cicero (Walter \& Lohse, 2018; Boundaryless S.r.1., 2019). The approaches of Cicero as well as Walter and Lohse include a comprehensive portfolio of tools to analyze the needs of platform participants in detail and to develop a validated concept for a digital platform. The high level of interactivity through supporting software solutions as well as the comprehensive analysis of the platform potential are to be positively emphasized. However, the multitude of tools and the required comprehensive know-how make the application considerably more difficult for the practitioner.

(2) Specific approaches to develop digital platforms: In order to successfully complete the platform construction, more than mere knowledge of a corresponding procedure is required. Against this background, approaches have been incorporated 
into the analysis of the state of the art, which deal in detail with the process of developing digital platforms. Zhu and Furr provide an approach to change products into platforms within four steps. The process for transforming products into platforms is preceded by an extensive analysis, which provides interesting orientation knowledge. On the positive side, the existing products and services of a company are taken into account and a step-by-step transformation is made possible. However, the four steps are only described superficially, which leaves some detailed questions open (Zhu \& Furr, 2016). Cusumano et al. provide another approach for the systematic development of a digital platform. Knowledge is made available in the form of principles for overcoming the chicken-and-egg problem. Especially companies with a low level of knowledge in the context of digital platforms can profit from this. An analysis of the initial situation is completely lacking; the authors rather assume a "green field" which is bypassing entrepreneurial practice. Moreover, the approach often remains relatively vague and lacks numerous details. For example, in the context of the business model, only the revenue model is considered (Cusumano et al., 2019).

(3) Pattern-based approaches to develop digital platforms: Patterns are present in many different domains. They occur wherever people are confronted with similar problems that can be solved with the same solution. An application of the pattern concept that is frequently mentioned in literature goes back to the architectural theorist Alexander, who developed 253 patterns for the design of cities and buildings in the 1970s (Alexander, 1979; Alexander et al., 1977). Since then, this idea has been taken up regularly, for example in software development. Software developers can use patterns to build on the knowledge of other and more experienced developers to solve their own problems (Kohls, 2014). Another example of the use of patterns is the design of business models. Through business model patterns, the success of particularly profitable companies becomes transparent and other companies are provided with the solution knowledge of these successful companies with the help of patterns (Amshoff et al., 2015).

For digital platforms, the pattern-related scientific literature has been dominated by approaches to the acquisition of platform participants-often also referred to as approaches to overcoming the chicken-and-egg problem. Leading works in this field come from Moazed and Johnson, Hagiu and Altman, as well as Evans and Schmalensee (Moazed \& Johnson, 2016; Hagiu \& Altman, 2017; Evans \& Schmalensee, 2016). The authors describe different ways to convince producers and consumers to use a platform. Another topic that is intensively discussed in the literature is the monetization of platforms. Leading works on this topic come from Parker et al. as well as L. C. Reillier and B. Reillier and Cusumano et al. (Cusumano et al., 2019; Parker et al., 2017; Reillier \& Reillier, 2017). From these works, patterns for the benefit-maximizing pricing of platform participants can be derived.

The mentioned and further approaches from the state of the art were examined for a possible utilization for the pattern-based development of digital platforms and were incorporated into the developed framework. The framework at hand was developed at the Heinz Nixdorf Institute using the Design Research Methodology (DRM) according to Blessing and Chakrabarti (2009). In the first phase of the research, the goal has been clarified including the theoretical foundation and the state of the 
art. In the second phase, a first descriptive study consisting of 40 interviews with management personalities within the machine building industry has been conducted (Engels et al., 2017). This study leads to a deeper understanding of the mechanisms of digital platforms and of the problems companies face while establishing own platforms or entering existing platforms. Following the interviews, we conducted a literature analysis which led to 79 potential platform patterns. The actual framework was developed in the third phase of the research within a prescriptive study. It is based on the findings of the first phase as well as further research (e.g., existing literature and best practices). The last phase of the work was a second descriptive study in which the developed methodology was evaluated. Eight companies participated in the validation and excluded 10 potential platform patterns because of their lack of practical and content-related relevance. The first phase of the validation led to 69 potential patterns. In order to eliminate redundancies in the remaining 69 potential patterns, these were bundled which led to the actual framework of 37 platform patterns.

\section{Proven Principles for the Development of Digital Platforms}

"The Way Digital Platforms Work and Why Established Enterprises Struggle with It" shows that established companies are not familiar with the way digital platforms work (Engels et al., 2017; Parker et al., 2017). In order to overcome the lack of knowledge in the platform economy and the resulting challenges, established companies can use patterns (see "Approaches to Develop Digital Platforms"). Patterns are connecting elements in a problem-solution relationship. Problems are obstacles that have to be overcome in the transition from an initial situation to a desired target state. If the transition is successful, the path to it is a solution. By using patterns, applying users can increase the efficiency of problem solving by using existing and abstract solutions for recurring problems (Amshoff et al., 2015). The present analysis takes up the definition of Alexander et al. A platform pattern therefore consists of a problem that companies have to overcome again and again when building digital platforms and a solution with which this problem can always be overcome (Alexander et al., 1977). These patterns are derived from reality and then documented in order to externalize the identified patterns. With the documentation, third parties gain access to the patterns and can apply them in reality (Kohls, 2014) (Fig. 4).

We use design fields of digital platforms to identify, classify, and differentiate between proven principals. Design fields of digital platforms are a homogeneous platform area in itself and can be designed separately from other fields. Existing frameworks and approaches for the development of digital platforms can be used to identify relevant design fields. We conducted a synthesis of existing literature concerning the process of establishing a digital platform and found seven design fields of digital platforms which could be tackled by using proven principals (see (Choudary, 2015; Walter \& Lohse, 2018; Edelmann, 2015)): 
Fig. 4 Relationship between obstacles, solution, and proven principle

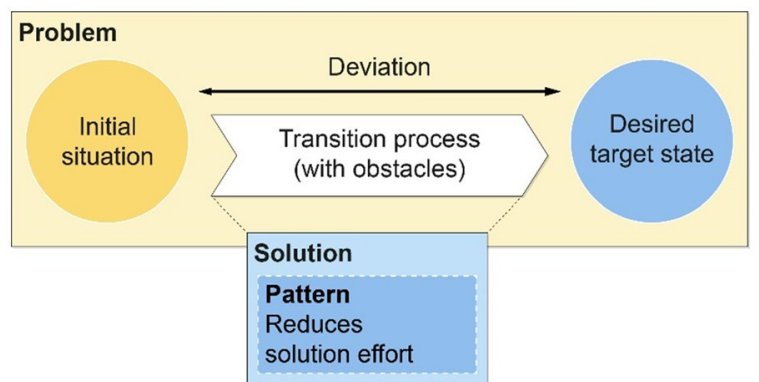

Participant acquisition: This design field includes measures that the owner of a platform has to take to convince producers and/or consumers of the benefits of a platform participation. In addition, the role of the acquired participants on the platform and the underlying motivation are determined within this design field.

Platform infrastructure: In order to enable high-quality transactions between the platform participants, the owner of the platform has to provide the necessary infrastructure. This guarantees the quality and relevance of the offerings and supports the participants in value creation and consumption.

Further ecosystem participants: The enterprise that develops a platform decides how to position itself in regard to third parties and whether an integration of certain third parties is necessary. With regard to the partners, it must be decided which functions the owner has to provide and which can be obtained by any third party producers. Possible advantages and disadvantages are to be included in the platform structure, so that the relationship of the platform owner to its ecosystem is optimally designed.

Anatomy of transaction: Enabling value adding transactions is the core value proposition of digital platforms. On a digital platform, information, value units, and payments are transferred between producers and consumers. The object of the platform structure is therefore, among other things, the design of a suitable transaction anatomy.

Monetarization: In order to ensure the long-term competitiveness of a digital platform, it is necessary to determine how activities on the platform can be monetarized. The platform owner determines which participant pays for a platform usage and which price structure is applied.

Value units: The object of every transaction is the exchange of a value unit between producers and consumers. The value unit must be characterized within the framework of the platform structure.

Channels: Channels describe which technical instruments are used by producers and consumers to access the platform. Possible channels are APIs, browsers, or smartphone applications.

The value units of a platform and the participant acquisition are undisputed in the existing literature. All approaches address these two design fields. The platform infrastructure and anatomy of transaction are not taken up without restriction by all approaches but are nevertheless mentioned by the majority. The design fields further 


\begin{tabular}{|c|c|c|}
\hline $\begin{array}{l}\text { Participant } \\
\text { Acquisition }\end{array}$ & $\begin{array}{l}\text { Platform } \\
\text { Infrastructure }\end{array}$ & $\begin{array}{l}\text { Further Ecosystem } \\
\text { Participants }\end{array}$ \\
\hline $\begin{array}{l}\text { Describes the measures an enterprise } \\
\text { has to implement, to convince consumers, } \\
\text { producers and/or partners to join the } \\
\text { platform. }\end{array}$ & $\begin{array}{l}\text { Includes all parts of infrastructure that the } \\
\text { platform enterprise has to provide to } \\
\text { enable high-quality and individualized } \\
\text { transactions between the participants of } \\
\text { the platform. }\end{array}$ & $\begin{array}{l}\text { Describes which functions are delegated } \\
\text { to additional participtans within the eco- } \\
\text { system and which functions should be } \\
\text { provided by the platform itself. }\end{array}$ \\
\hline $\begin{array}{l}\text { Anatomy of Trans- } \\
\text { action }\end{array}$ & Monetarization & Value Unit \\
\hline $\begin{array}{l}\text { Information, value units and payments } \\
\text { are transferred between the participants } \\
\text { of a platform. The anatomy of these } \\
\text { transactions is to be designed within the } \\
\text { development of a platform. }\end{array}$ & $\begin{array}{l}\text { It is necessery to define how a digital } \\
\text { platform should generate income, to be } \\
\text { succesful in the long run. }\end{array}$ & $\begin{array}{l}\text { The cause of each transaction within a } \\
\text { digital platform is the exchange of a value } \\
\text { unit. It is necessary to characterize } \\
\text { these value units precisly within the } \\
\text { development of a digital platform }\end{array}$ \\
\hline
\end{tabular}

Fig. 5 Design fields of a digital platform

ecosystem participants, monetarization and channels are controversially discussed by the existing approaches. We used our knowledge of 40 conducted interviews with management personalities (Engels et al., 2017) within the machine building industry to decide which design fields we could tackle by using existing approaches. The interviews and explorative projects within the machine building industry showed that the channels producers and consumers use to access the platform are relatively easy to choose. We therefore decided not to search for proven principles for this design field. The six remaining fields are shown in Fig. 5.

We used these design fields to search for proven principles. The goal was a catalogue consisting of patterns (Alexander et al., 1977). We researched and compiled
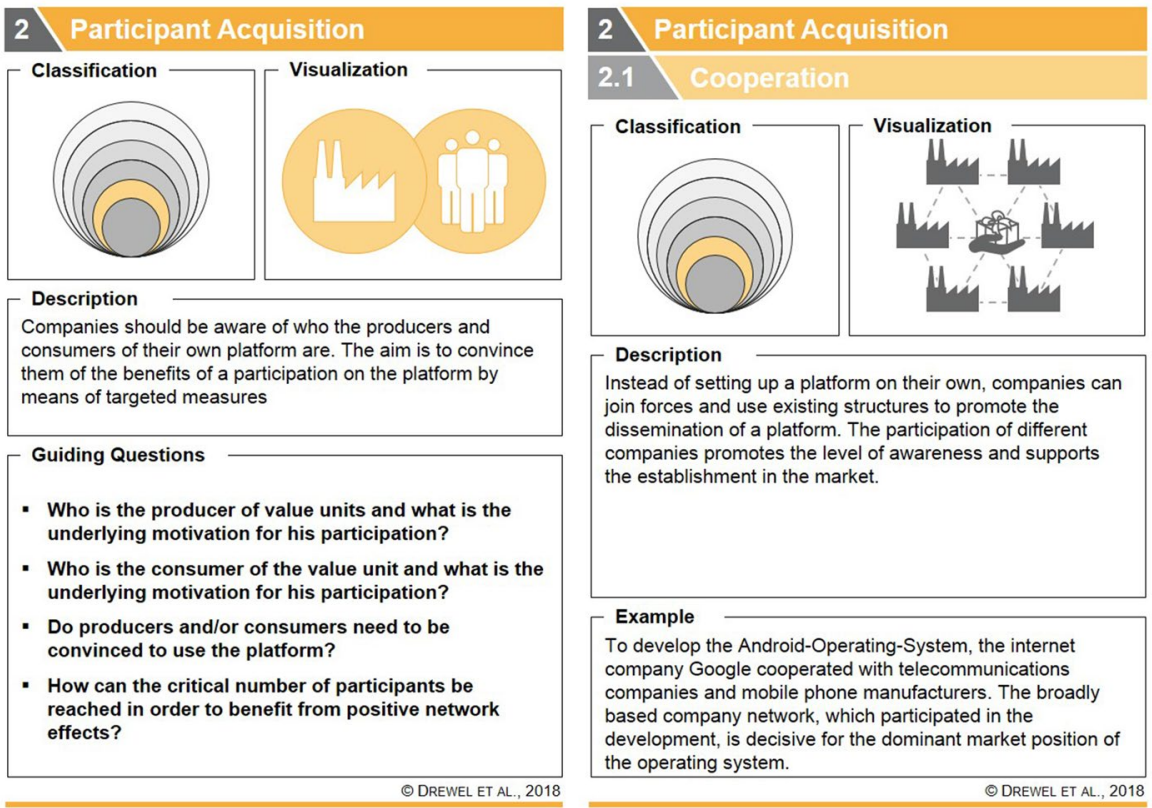

Fig. 6 Exemplary pattern "cooperation" 
potential patterns in a collection and eliminated those of low relevance. A cluster algorithm bundled the remaining content so that proven principles could be derived. We documented the determined platform patterns in a uniform notation scheme. Figure 6 shows the design field participant acquisition with the exemplary pattern cooperation. The design fields are characterized by a classification, a description, and guiding questions. The classification specifies the sequence in which the design fields should be dealt with (see "How to Use Patterns for Digital Platforms"). Each associated pattern is characterized by a description and at least one successful application example.

We transferred the identified patterns into a structure-giving catalogue which serves as an orientation framework for the pattern application. The catalogue is universally valid and can be used independently from the task at hand. Furthermore, new patterns can be added once they are identified which makes the catalogue a growing source of knowledge. We identified 37 platform patterns (see Fig. 7).

\section{How to Use Patterns for Digital Platforms}

A superordinate process is used as an orientation framework for the platform patterns. The process is based on the six design fields of digital platforms and systematizes the application of the patterns. The starting point is the value unit
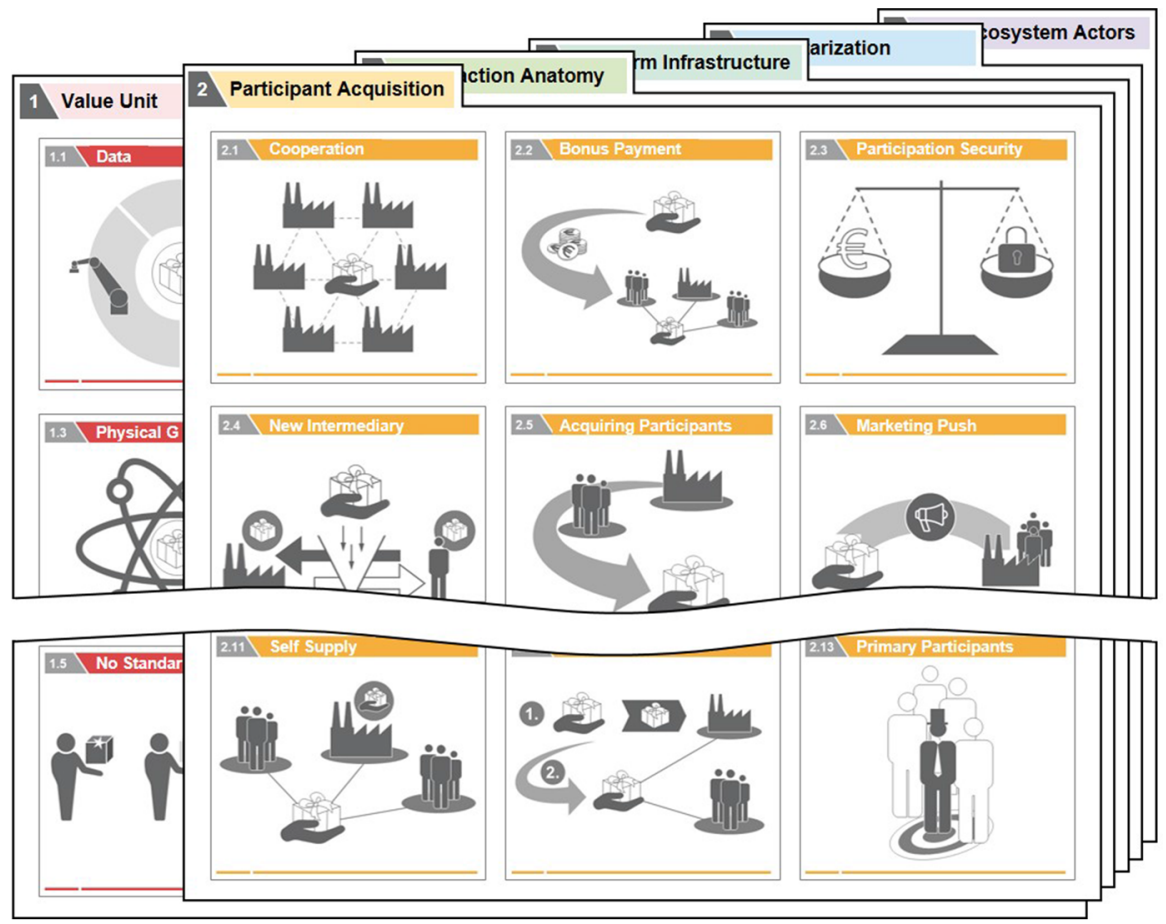

Fig. 7 Catalogue of consisting patterns with design field participant acquisition on front 


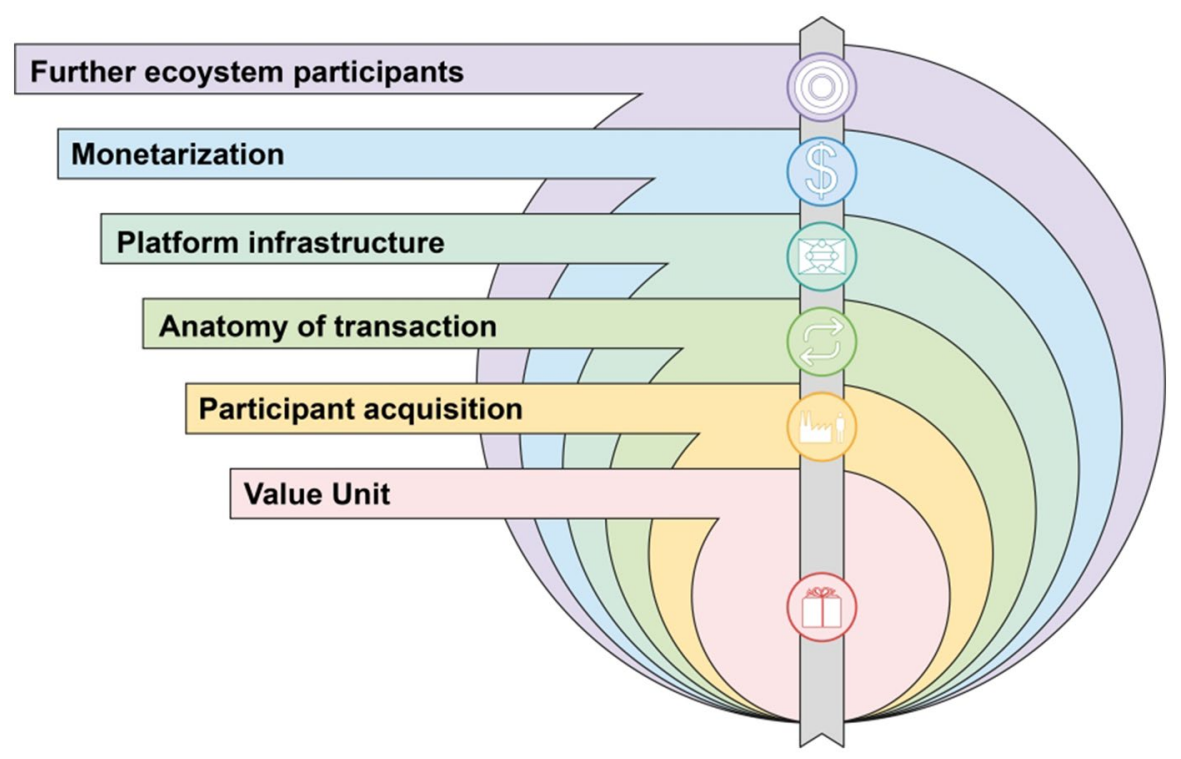

Fig. 8 Sequence of application for platform patterns

of the key interaction (first layer) as the platforms central promise of value. The key interaction is based on an exchange of value units between producers and consumers (see Fig. 3). The second layer is the acquisition of participants, which is crucial for the scaling of a digital platform. Besides the value unit and the participant acquisition, the anatomy of transaction is part of the key interaction. To determine a suitable anatomy of transaction, the exchange of information, value units, and payments is worked out in the third layer. After designing the key interaction, the platform infrastructure needs to be shaped. The infrastructure contains corresponding functions which are combined to bundles. Subsequently, the design of the monetarization (fifth layer) of the platform is carried out with the objective of ensuring the long-term viability of the platform. For this purpose, parts of the created values must be retained by the owner of the platform. The process ends with the decision as to how openly the platform owner will position the platform for further ecosystem participants (sixth layer). This sequence of designing a digital platform is based on the key interaction and describes a platform development directed from the inside to the outside (Choudary, 2015). The sequence is presented in Fig. 8.

The presented sequence enables companies to decide in which order they should implement the platform patterns. Each design field is characterized by guiding questions which help to decide which patterns are applicable. In the following, approaches for the application of platform patterns are presented. First, we describe how platform ideas can be generated by using platform patterns. Building on this, we describe a pattern-based development of a platform concept. In addition, platform concepts and already existing digital platforms can be characterized in detail with the help of platform patterns. 
Pattern association:

Assignment of a suitable platform pattern to an existing platform idea.
Pattern confrontation:

Development of platform ideas through confrontation with identified platform patterns.
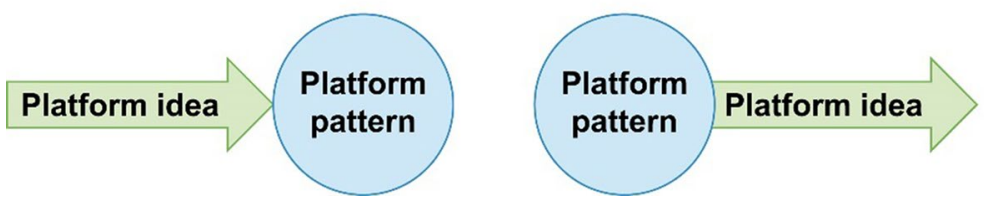

Fig. 9 Principles to generate ideas for platforms in accordance with Amshoff et al., (2015)

\section{Platform Patterns as a Way to Generate New Ideas}

The developed patterns can be used as a creativity technique to generate new ideas for digital platforms. As stated by Csik, patterns have a positive effect on the results of creativity processes. The effect is based on the fact that patterns cause certain stimuli which promote creativity (Csik, 2014). In extension of Gassmann et al., the generation of ideas by means of patterns is based on two principles: (1) pattern association and (2) pattern confrontation (Amshoff et al., 2015; Gassmann et al., 2014). The principles are shown in Fig. 9.

Pattern association: Here, an idea for a digital platform is already available in advance, which can be assigned to a pattern from the framework. In this way, existing ideas can be further concretized (Amshoff et al., 2015).

Pattern confrontation: With this principle, a pattern is chosen at random and presented to the persons involved. This provocation allows existing thought patterns to be broken through; completely new ideas for digital platforms with the potential for radically new functions emerge (Gassmann et al., 2014).

We used our framework for both principles within various workshops and validated its applicability to generate new ideas for digital platforms. The validation was carried out as part of a research project to initiate a digital marketplace for artificial intelligence applications for product engineering. In the following, an exemplary approach to pattern association and pattern confrontation is presented.

\section{Pattern Association}

The starting point of the pattern association is an idea provided in advance. In our workshops we discussed the idea of a marketplace for applications of artificial intelligence in product engineering. The aim of the workshop was to concretize this idea on the basis of the identified patterns. The workshop was carried out with 35 participants from SMEs, research institutes and associations and federations within the field of product engineering. Figure 10 shows the concept of the workshop. The workshop participants used characteristic platform participnts of the marketplace and their problems to generate and improve their ideas to form a holistic concept for the AI-Marketplace. 


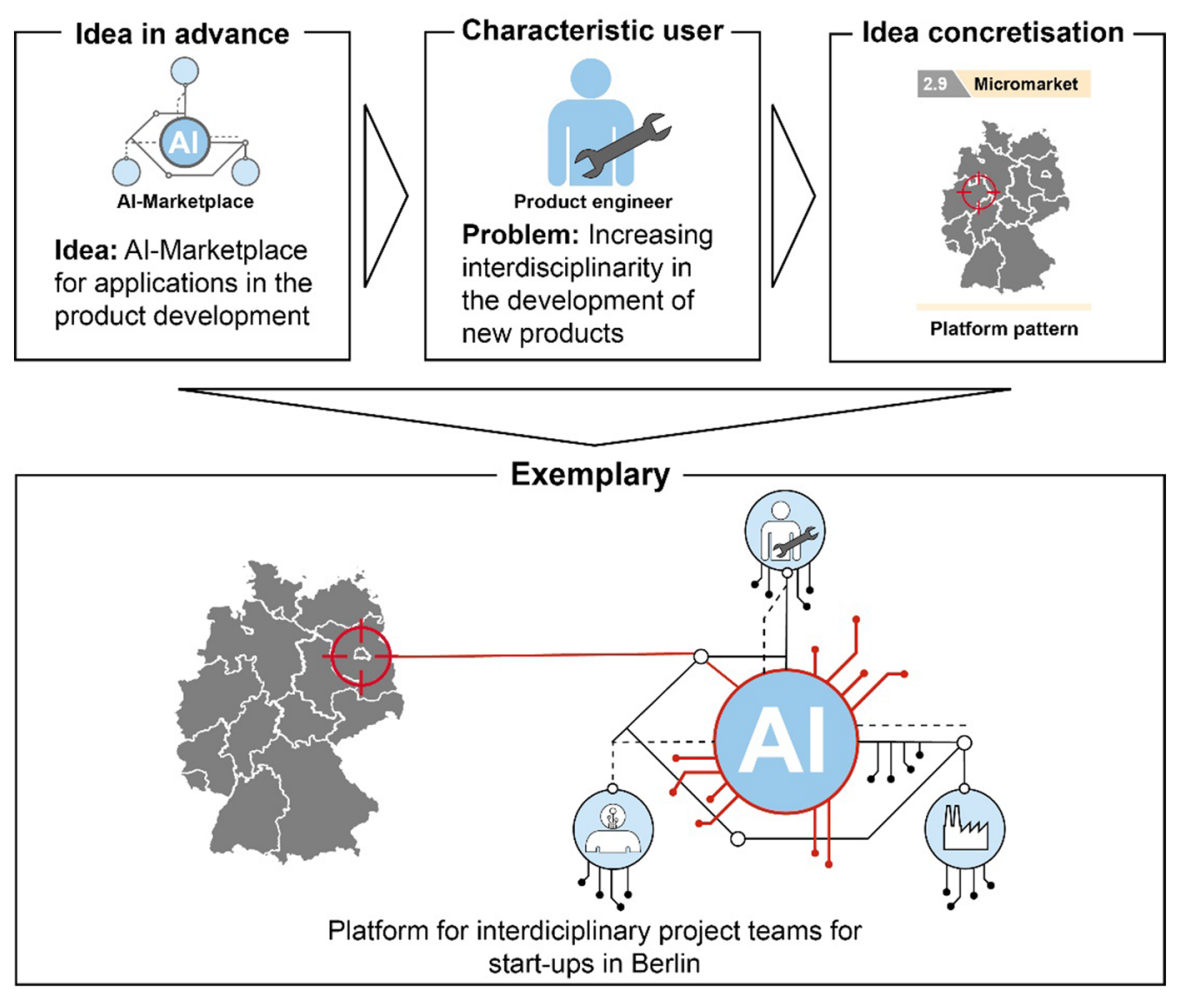

Fig. 10 Pattern association workshop to generate ideas for a digital marketplace

We conducted a second workshop with 30 participants with the same task. Within the second workshop, we did not use the patterns for digital platforms but also the characteristic platform participants of the digital marketplace. We found that the group without the patterns had considerable difficulties in developing ideas for such a marketplace. The concept of digital marketplaces had to be explained more than once and in much more detail. Moreover, the generated ideas were often not applicable for a digital marketplace but rather for a "simple" application for a potential marketplace. The differences between the idea generation with patterns and without patterns are presented in "Differences in the Generation of Ideas with and Without Patterns".

\section{Pattern Confrontation}

We conducted another workshop to generate ideas for a digital platform based on the concept pattern confrontation. The ideas were generated with 38 participants from research institutes and employees of machine learning companies. The participants used the platform patterns to directly generate ideas for an 


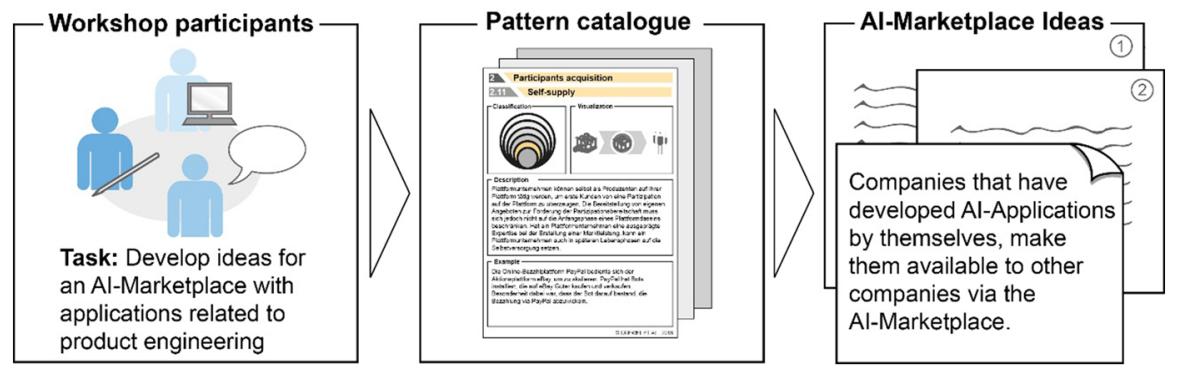

Fig. 11 Pattern confrontation to generate ideas for a digital marketplace

AI-Marketplace (see Fig. 11). The patterns were randomly selected from the pattern catalogue in order to determine the greatest possible heterogeneity between the different ideas.

We found that the participants of the workshop understood the new concept of digital platforms much faster and easier than in workshops with a similar task but without the pattern confrontation. Moreover, the participants were enthusiastic about the task and developed quite radical new ideas. The differences between the two approaches and workshops without patterns are presented in "Differences in the Generation of Ideas with and Without Patterns".

\section{Differences in the Generation of Ideas with and Without Patterns}

Within our workshops, we found clear distinguishing factors between the generation of ideas for a digital platform by pattern association, pattern confrontation, and without any patterns at all. The analysis of the factors is based on one workshop for each approach with 30 to 38 participants. Within these workshops, we formed small groups of five participants which gives us six to eight data sets for each approach. The presented findings are based on the results of the workshops which can be grouped into three categories:

Hard facts: Number of ideas

Soft facts: Feasibility of the ideas, radicality of ideas, user orientation of ideas

Gut feeling: Understanding of the task, enthusiasm of the participants

Figure 12 represents the findings of the workshops. The qualitative results show that the application of patterns leads to better results and better workshops. While both approaches work well, we could still see clear differences between the pattern association and pattern confrontation. The pattern association generates more ideas with a high feasibility and user orientation. The pattern confrontation on the other hand delivers less, but much more radical ideas. Also, the understanding of the task and the enthusiasm of the participants is a little higher than by pattern association. In order to summarize the findings, it can be stated that the pattern association is particularly suitable for workshops with the goal of many user-oriented ideas. 
Fig. 12 Distinguishing factors between the generation of ideas for a digital platforms by pattern association, confrontation, and without patterns

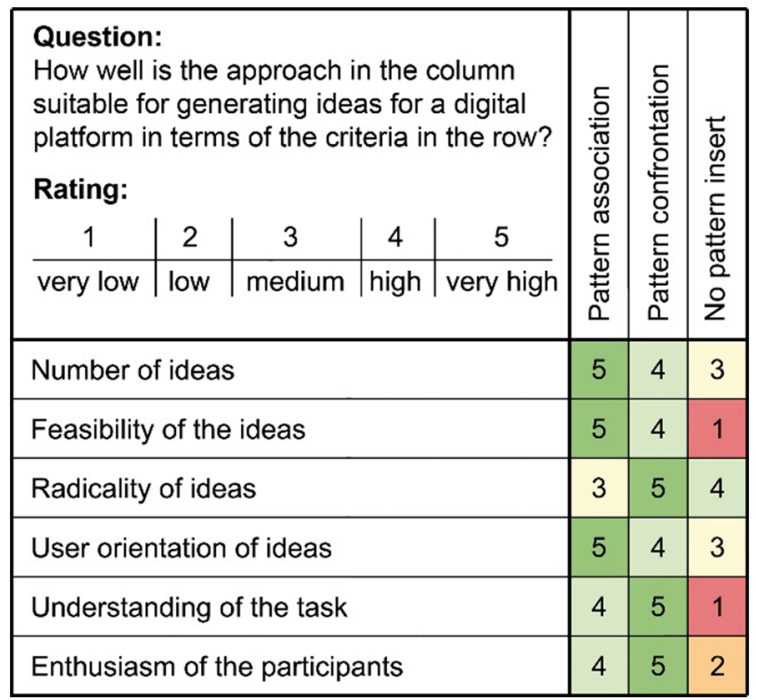

Pattern confrontation, on the other hand, should be used to generate more radical ideas. In addition, both approaches can be combined, e.g., by first developing ideas via characteristic platform participants of a possible marketplace and the association of patterns. In order to further develop these ideas, new patterns from the catalogue can then be used.

\section{Pattern-Based Development of Digital Platforms}

The pattern-based development of digital platforms includes the phases ideation, conception, and development of digital platforms (Amshoff et al., 2015). The basic

2. Platform concept

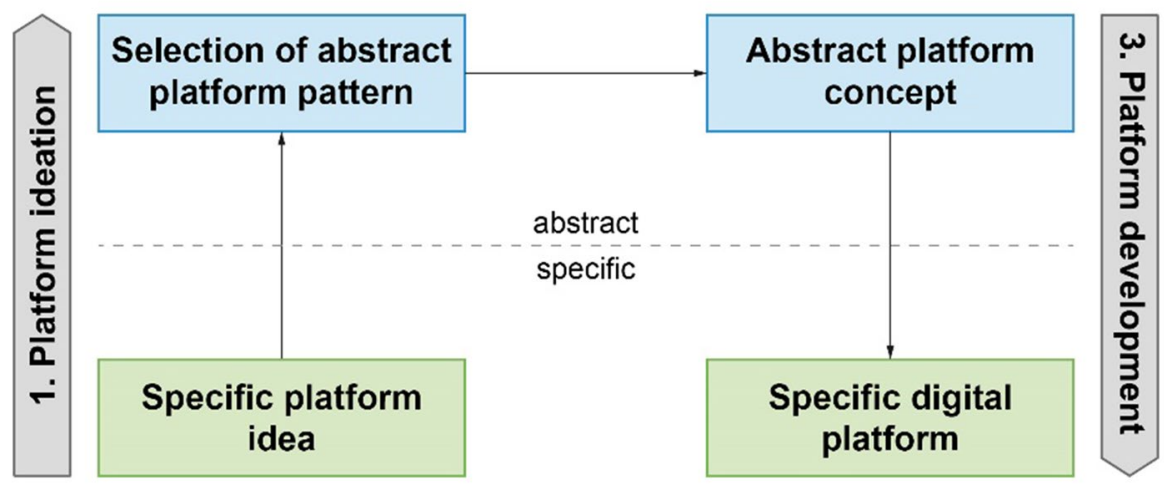

Fig. 13 Basic principle of pattern-based platform development (Amshoff, 2015) 


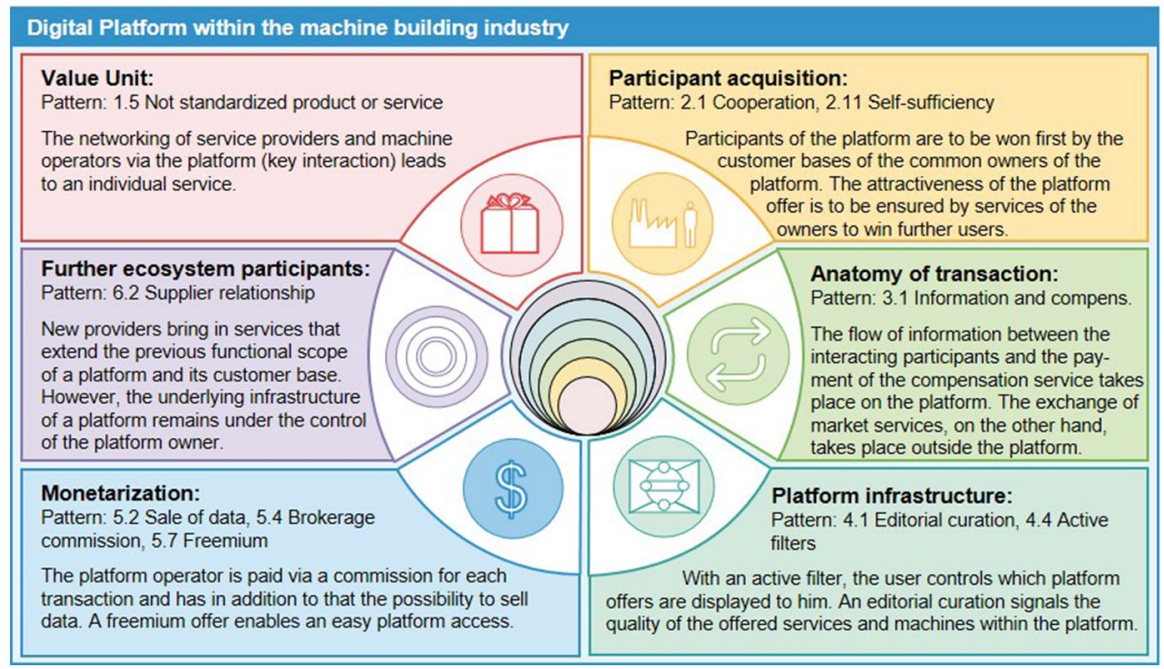

Fig. 14 Concept for a digital platform within the machine building industry

principle is shown in Fig. 13. Following Amshoff, an abstract and a specific area are distinguished. The specific area describes the point of view of a company which wants to realize a platform idea. The abstract area contains the generalization of the platform in the form of patterns. The different phases of the pattern-based development of digital platforms are explained below. This process must be conducted every time a new platform is initiated.

Part of the platform ideation is the formulation of a specific platform idea, which is called platformization mission. Subsequently, the process for applying platform patterns (beginning "How to Use Patterns for Digital Platforms") is used to assign patterns to each of the design fields according to the platform mission described. The guiding questions provided for this purpose support the applying user when assigning appropriate patterns to the design fields. Once all the design fields are characterized by answering the guiding questions and applying the patterns, a company can define its concept for a digital platform. For this purpose, the individually selected patterns are brought together, avoiding the combination of conflicting patterns and taking into account the choice of patterns that favor each other. This pattern combination corresponds to the core of the platform conception. The result of this analysis step is an abstract platform concept. The concept is documented and is exemplarily shown in Fig. 14. The platform development addresses the transformation of the abstract platform concept into an elaborated and company-specific digital platform.

\section{Characterization of Popular Platform Enterprises}

Platform companies currently have an unprecedented economic dominance. Established companies not only find it difficult to participate in the economic rise of the 


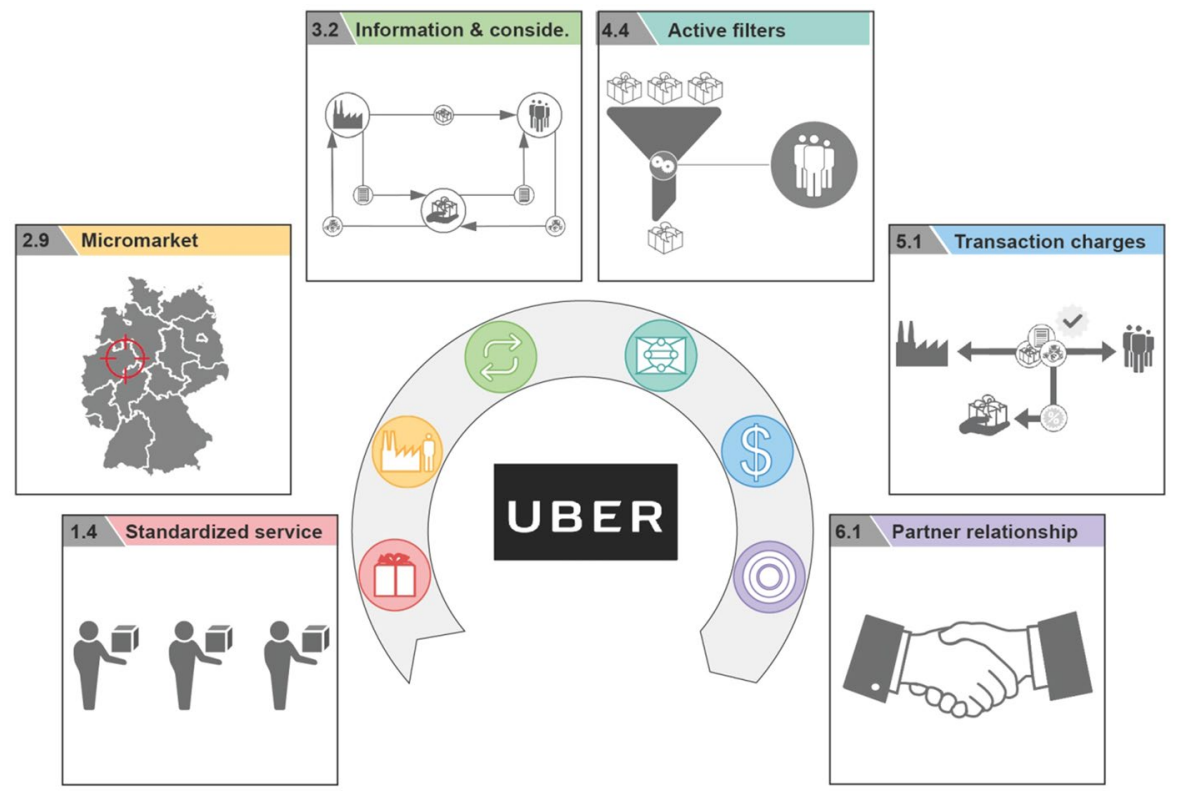

Fig. 15 Characterization of the B2C platform Uber with platform patterns (extract)

platform economy. It is often the case that they do not even have the necessary platform knowledge to understand the business activities of major platform companies. Against this background, the identified platform patterns can be used to make the business activities of successful platform companies transparent. The investigation of these existing platform companies allows to reveal potential gaps in the existing pattern catalogue. Moreover, established companies gain insights into platform companies and can understand what they do differently. This offers the possibility of generating new ideas, e.g. by addressing the weaknesses of existing platforms (Köster, 2014). The patterns are then used to generate ideas for better solutions (Markides, 2008).

In the following, it is exemplary presented with which patterns the well-known B2C platform Uber (see Fig. 15) became successful and which patterns were used for the mentioned B2B platform "AI-Marketplace" (see Fig. 16). Uber is a platform for the brokerage of driving services and thus relies on the value unit (level 1) pattern standardized service. In order to attract both drivers and passengers to the platform, various patterns of participant acquisition were and are used (level 2). One example is the micromarket. By using this pattern, Uber initially set up its services locally limited in selected cities such as San Francisco to be able to benefit more quickly from positive network effects. In anatomy of transaction (level 3 ), the pattern information and return is used. This means that only the value unit (the trip) is directly transmitted between driver and passenger outside the platform. The exchange of information and money takes place via the platform. For the design of the platform infrastructure (level 4), the exemplary pattern active filter is used. Passengers actively transmit data to Uber so that the best driver can 


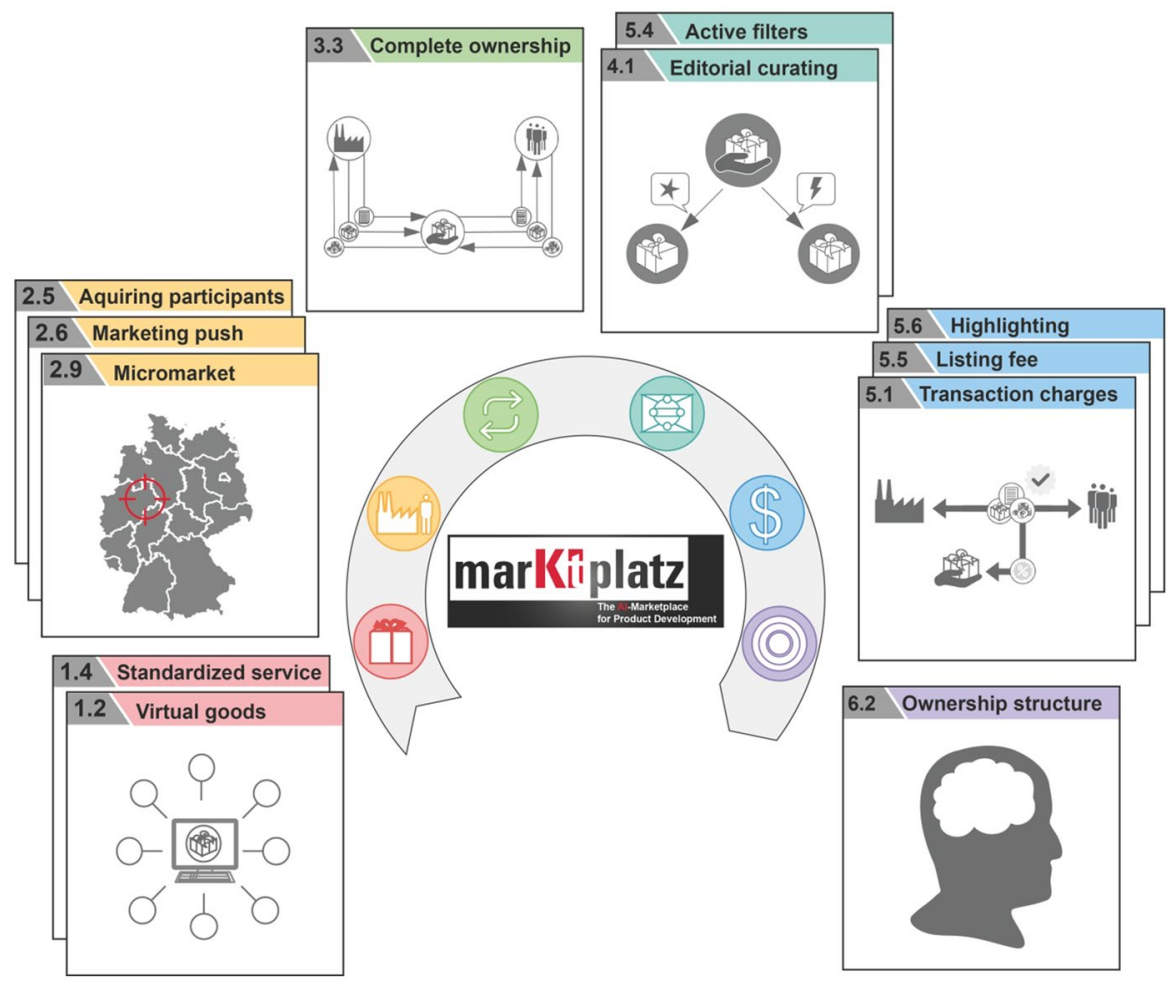

Fig. 16 Characterization of the B2B platform AI-Marketplace with platform patterns

be provided to the consumer. The fifth level monetization is served with the pattern transaction fees. By using this pattern, Uber retains a portion of the passenger's compensation payment for each completed transaction between driver and passenger. At the final layer further ecosystem participants, Uber relies on the pattern partner relationship and offers external partners access to the platform through APIs to increase the functionality.

In addition to the transport service provider Uber, the AI-Marketplace will be presented as an example of a B2B platform (see Fig. 16). The AI-Marketplace is a digital platform that connects producers of AI-applications for the product development with manufacturing companies. For example, manufacturing companies can have existing design drawings optimized using an AI-application (e.g. in terms of material consumption or stiffness). Virtual goods (AI-applications) and standardized services (AI-Consulting) are the value provided by the marketplace (level 1) of this platform. The platform starts in a small region of Germany and uses an existing innovation-ecosystem (it's OWL). The companies within this ecosystem trust each other and some of these companies are even part of the project behind the AI-Marketplace. The pattern micromarket was therefore used to attract initial participants. Further on, the patterns marketing push and acquiring 
participants were used to attract platform participants from whole Germany (level 2). Producers of AI-Applications and manufacturing companies were already in contact before the AI-Marketplace came into existence. The AI-Marketplace has established itself between these actors by facilitating exchanges and offering complementary value units. For the transaction anatomy (level 3), the pattern complete ownership is used. Value unit, information, and monetary consideration are handled via the digital platform. Editorial curating as well as active filter are used for the platform infrastructure (level 4). The AI-Marketplace charges transaction fees for the procurement of AI-applications. In addition, a listing fee is charged for selected advertisements and highlighting of offers is made possible in order to generate further revenues (level 5). The AI-Marketplace is open for further owners, which will mostly be from the leading edge innovation-ecosystem it's OWL. Therefore, the pattern ownership structure is used (level 6).

The presented examples show that the pattern catalogue can be used to characterize any given digital platform. We found that by doing so, companies can understand the business of potential competitors and were even able to develop their own digital platforms. Moreover, some companies used the characterization of potential competing platforms in order to improve their own solution.

\section{Summary and Outlook}

Digital platforms are becoming increasingly widespread in the industry and companies are on their way into the platform economy. While the awareness of the economic potential of the platform model is growing, many established companies have considerable difficulties mastering the challenges of participating in the platform economy. An exemplary challenge is the completely new form of value creation of platform companies, which is largely unknown to manufacturing companies. To overcome the challenges of the platform economy, clever strategic action is more important than ever. A first starting point for entering the platform economy is the methodical approach presented here.

The patterns and methods provided help to master the entry into the platform economy and to reduce uncertainties. Patterns represent proven principals and can thereby provide valuable know-how for business activities in the platform economy. We identified 37 patterns and structured them in a catalogue which makes the patterns useable. To do so, we provide a process model which systematizes the design fields of a digital platform. Due to the high dynamics and short innovation cycles, the catalogue provided should be regularly reviewed and updated or expanded. It goes without saying that the entry into the platform economy does not stop with the development of promising concepts. Further approaches, such as specification techniques to describe platforms, are needed to support companies in coping with the transformation from pipeline to platform markets. The characterization of the first platforms has yielded promising results. In the future, a large number of established platforms will be characterized using the patterns to identify common combinations. Moreover, we were able to gain some additional theoretical insights, e.g., (a) platform categories are often taken up in the scientific discussion but a uniform 
differentiation does not exist yet. (b) Besides technical knowledge gaps companies often do not know how to earn money with platforms. (c) The manufacturing industry is particularly concerned about the loss of consumer access due to digital platforms.

Funding Open Access funding enabled and organized by Projekt DEAL.

Open Access This article is licensed under a Creative Commons Attribution 4.0 International License, which permits use, sharing, adaptation, distribution and reproduction in any medium or format, as long as you give appropriate credit to the original author(s) and the source, provide a link to the Creative Commons licence, and indicate if changes were made. The images or other third party material in this article are included in the article's Creative Commons licence, unless indicated otherwise in a credit line to the material. If material is not included in the article's Creative Commons licence and your intended use is not permitted by statutory regulation or exceeds the permitted use, you will need to obtain permission directly from the copyright holder. To view a copy of this licence, visit http://creativecommons.org/ licenses/by/4.0/.

\section{References}

Alexander, C. (1979). The timeless way of building (24th ed.). New York, NY: Oxford Univ. Press.

Alexander, C., Ishikawa, S., \& Silverstein, M. (1977). A pattern language: Towns, buildings, construction, 18 th edn.

Alstyne, M. W., Parker, G. G., \& Choudary, S. P. (2016). Pipelines, platforms and the new rules of strategy. Harvard Business Review, 94(4), 54-62.

Altman, E. J., Nagle, F., \& Tushman, M. L. (2013). Innovating without information constraints: Organizations, communities, and innovation when information costs approach zero [Online], Cambridge, Mass. (Harvard Business School working paper). Available at http://www.hbs.edu/faculty/ Pages/item.aspx?num $=45932$

Amshoff, B., Dülme, C., Echterfeld, J., \& Gausemeier, J. (2015). Business model patterns for disruptive technologies. International Journal of Innovation Management, 19(03), 1540002.

Baums, A. (2015). Analyse: Was sind digitale Plattformen? In A. Baums, M. Schlössler, \& B. Scott (Eds.), Kompendium Industrie 4.0: Wie digitale Plattformen die Wirtschaftverändern - und wie die Politik gestalten kann (pp. 13-24). Berlin: Kompendium Digitale Standortpolitik.

Blessing, L. T. M. \& Chakrabarti, A. (2009). DRM, a Design Research Methodology [Online], London, Springer London. Available at http://site.ebrary.com/lib/alltitles/docDetail.action?docID=10310350

Boundaryless. (2019). Platform Design Toolkit 2.2 - User Guide.

Caillaud, B., \& Jullien, B. (2003). Chicken \& egg: Competition among intermediation service providers. The RAND Journal of Economics, 34(2), 309.

Choudary, S. P. (2015). Platform scale: How an emerging business model helps startups build large empires with minimum investment. Boston: Platform Thinking Labs Pte.

Csik, M. (2014). Muster und das Generieren von Ideen für Geschäftsmodellinnovationen [Online], Bamberg. Available at http://www1.unisg.ch/www/edis.nsf/SysLkpByIdentifier/4263

Cusumano, M. A., Gawer, A., \& Yoffie, D. B. (2019). The business of platforms: Strategy in the age of digital competition, innovation, and power. New York, NY: HarperCollins Publishers.

Lerch, C., Meyer, N., Horvat, D., Jackwerth-Rice, T., Jäger, A., Lobsiger, M., \& Weidner, N. (2019). Die volkswirtschaftliche Bedeutung von digitalen B2B-Plattformen im Verarbeitenden Gewerbe.

Drewel, M., Gausemeier, J., Koldewey, C. \& Özcan, L. (2018). 'Pattern based development of digital platforms', Proceedings of ISPIM Connects Fukuoka: Solving Challenges Through Innovation. Fukuoka, Japan, 2.12.-5.12.2018. Fukuoka, ISPIM.

Edelmann, B. (2015). How to launch your digital platform. Harvard Business Review, Heft, 4, 90-97.

Eisenmann, T., Parker, G. G., \& Alstyne, M. W. (2006). Strategies for two-sided markets. Harvard Business Review, Heft, 10, 92-101.

Engels, G., Plass, C., \& Rammig, F. J. (Eds.). (2017). IT-Plattformen für die Smart Service Welt (acatech Diskussion). München: Herbert Utz Verlag. 
Evans, D. S., \& Schmalensee, R. (2016). Matchmakers: The new economies of multisided platforms. Boston: Harvard Business Review Press.

Evans, P. C., \& Gawer, A. (2016). 'The Rise of the Platform Enterprise: A Global Survey', The Emerging Platform Economy Series, No. 1.

Farrell, J., \& Saloner, G. (1992). Converters, compatibility, and the control of interfaces. The Journal of Industrial Economics, 40, 9-35.

fortiss Gmbh. (2016). Digitale Transformation: Wie Informations- und Kommunikationstechnologie etablierte Branchen grundlegend verändern, München, fortiss $\mathrm{GmbH}$.

Funk, J. L. (2009). Direct network effects, small-world networks, and industry formation. Telecommunications Policy, 33(5-6), 241-252.

Gassmann, O., Frankenberger, K., \& Csik, M. (2014). The business model navigator: 55 models that will revolutionise your business, Harlow, England, London, New York, Boston, San Francisco, Pearson.

Hagiu, A., \& Altman, E. J. (2017). Finding the platform in your product. Harvard business review: HBR, 95(4), 94-100.

Härting, N. (2015). Haftungsverschärfungen für Plattform-Betreiber: Der Beginn des Zeitalter der Plattformregulierung? In A. Baums, M. Schlössler, \& B. Scott (Eds.), Kompendium Industrie 4.0: Wie digitale Plattformen die Wirtschaftverändern - und wie die Politik gestalten kann (pp. 98-107). Berlin: Kompendium Digitale Standortpolitik.

Jaekel, M. (2017). Die Macht der Digitalen Plattformen: Wegweiser Im Zeitalter Einer Expandierenden Digitalsphäre und Künstlicher Intelligenz [Online], Wiesbaden, Vieweg. Available at https:// ebookcentral.proquest.com/lib/gbv/detail.action?docID $=5122211$

Katz, M., \& Shapiro, C. (1986). Product compatibility choice in a market with technological progress. Oxford Economic Papers, 38, 146-165.

Kempe, C. (2011). 'Die größten Unternehmen im Wandel der Zeit', Portfolio Institutionell, Ausgabe 1.

Kohls, C. (2014). The theories of design patterns and their practical implications exemplified for e-learning patterns, Eichstätt-Ingolstadt, Katholische Universität Eichstätt-Ingolstadt, Diss., 2014, Eichstätt-Ingolstadt, Katholische Universität Eichstätt-Ingolstadt.

Koldewey, C., Evers, H. H., Dumitrescu, R., Frank, M., Gausemeier, J., \& Reinhold, J. (2019). 'Development Process for Smart Service Strategies: Grasping the Potentials of Digitalization for Servitization', proceedings of The XXX ISPIM INNOVATION CONFERENCE - Celebrating Innovation - 500 Years Since Da Vinci. Florence, Italy, 16-19 June. Florence, ISPIM.

Köster, O. (2014). Systematik zur Entwicklung von Geschäftsmodellen in der Produktentstehung (Dissertation, Fakultät für Maschinenbau, Universität Paderborn) [Online], Paderborn. Available at https://katalog.ub.uni-paderborn.de/records/PAD_ALEPH001727007

Libert, B., Beck, M., \& Wind, J. (2016). The network imperative: How to survive and grow in the age of digital business models. Boston: Harvard Business Review Press.

Linz, C., Müller-Stewens, G., \& Zimmermann, A. (2017). Radical Business Model Transformation: Gaining the Competitive Edge in a Disruptive World [Online], London, Kogan Page. Available at https://ebookcentral.proquest.com/lib/gbv/detail.action?docID=4773646

Markides, C. (2008). Game-changing strategies: How to create new market space in established industries by breaking the rules [Online], San Francisco, CA, Jossey-Bass. Available at http://search. ebscohost.com/login.aspx $?$ direct $=$ true $\&$ scope $=$ site $\& \mathrm{db}=$ nlebk $\& \mathrm{db}=\mathrm{nlabk} \& \mathrm{AN}=233134$

Moazed, A., \& Johnson, N. L. (2016). Modern monopolies: What it takes to dominate the 21st-century economy. New York: Martin's Press.

O’Sullivan, A., \& Sheffrin, S. M. (2003). Economics: Principles in action. Needham, Mass: Prentice Hall.

Parker, G., van Alstyne, M., \& Choudary, S. P. (2017). Platform revolution: How networked markets are transforming the economy - and how to make them work for you, New York, London, W.W. Norton \& Company.

Payment \& Banking. (2019). Infografik: Die wertvollsten Unternehmen (1990-2018) [Online]. Available at https://paymentandbanking.com/die-wertvollsten-unternehmen-1990-2018/(Accessed 1 July 2019).

Porter, M. E. (1985). Competitive Advantage - Creating and Sustaining Superior Performance. New York: The Free Press.

Reillier, L. C., \& Reillier, B. (2017). Platform Strategy: How to unlock the power of communitites and networks to grow your business, London, Routledge.

Shapiro, C., \& Varian, G. R. (1998). Information rules: A strategic guide to the network economy. Boston: Harvard Business Review Press. 
Tiwana, A. (2014). Platform ecosystems: Aligning architecture, governance, and strategy [Online], Waltham, Morgan Kaufmann. Available at http://proquest.tech.safaribooksonline.de/9780124080669

Walter, M., \& Lohse, M. (2018). Platform Innovation Kit 3.0: User Guide, Dresden, Platform \& Blockchain Innovation Lab.

Zhu, F., \& Furr, N. (2016). Products to platforms: Making the leap. Harvard Business Review, 94(4), $72-78$.

Publisher's Note Springer Nature remains neutral with regard to jurisdictional claims in published maps and institutional affiliations.

\section{Authors and Affiliations}

\section{Marvin Drewel ${ }^{1}\left[\right.$ - Leon Özcan ${ }^{1} \cdot$ Jürgen Gausemeier ${ }^{1} \cdot$ Roman Dumitrescu $^{1}$}

Leon Özcan

leon.oezcan@hni.uni-paderborn.de

Jürgen Gausemeier

juergen.gausemeier@hni.uni-paderborn.de

Roman Dumitrescu

roman.dumitrescu@hni.uni-paderborn.de

1 Heinz Nixdorf Institut, Universität Paderborn, Paderborn, Germany 